9. Die Bogenqüblung der Vorlage wurde übernommen, jedocb stillschweigend ergänzt, da jewvils nur die ersten fünf Blätter $(r)$ eines Bogens durchgezäblt sind. Offensicbtlicbe Febler wurden obne Vermerk verbessert.

\title{
III
}

Bei den Vorarbeiten $z^{u}$ dieser Edition wurden Auskinfte von allen einscblägigen deutschen und außerdeutschen Bibliotbeken eingebolt, um den Überlieferungsbestand zu sicbten. Allen Bibliotbeken, die die Sucbkarteien bereitwillig bearbeitet baben, sei biermit gedankt. $\mathrm{Zu}$ besonderem Dank füblt sich der Herausgeber der Fürstlich Fürstenbergischen Hofbibliotbek Donauescbingen, der Osterreichischen Nationalbibliothek Wien und der Herzog August Bibliothek Wolfenbüttel verpflicbtet, die ibre zeitgenössischen Ausgaben für längere Zeit an die Universitätsbibliotbek Regensburg zur Verfïgung stellten. Beim Kollationieren wie bei den zablreichen Korrekturen war mir meine Frau eine quverlässige Mitarbeiterin.

\section{Inhalt des ersten Bandes}

Ezechias $. . . \ldots \ldots \ldots \ldots \ldots \ldots \ldots \ldots \ldots \ldots \ldots, \quad 1$

Zorobabel $\ldots \ldots \ldots \ldots \ldots \ldots \ldots \ldots \ldots \ldots \ldots, \quad 25$

Ioseph $\ldots \ldots \ldots \ldots \ldots \ldots \ldots \ldots \ldots \ldots \ldots \ldots, \quad 71$

Beel ................................. 159

Nacbwort des Herausgebers ................... 297 



\title{
Ausgaben Deutscher Literatur
} des XV. bis XVIII. Jahrhunderts

unter Mitwirkung von KäTHE KAHLENBERG herausgegeben von HaNS-Gert RoLOFF

\section{Johann Christoph Gottsched} Ausgewählte Werke

herausgegeben von Jonснiм Brake. Etwa 14 Bände

Bisher erschienen die Bände 1 und 4

\section{Georg Wickram Sämtliche Werke}

herausgegeben von Hans-Gert Roloff. Etwa 14 Bände

Bisher erschienen die Bände 1-3, 5, 12

\author{
Johann Rist \\ Sämtliche Werke
}

Unter Mitwirkung von Helga Mannack

herausgegeben von Eberhard Mannack. Etwa 10 Bände

Bisher erschien Band 1

\section{Alexander Seitz}

Sämtliche Schriften

herausgegeben von Peter Ukena. 4 Bände

Ein ausfübrlicher Prospekt der Reibe stebt zur Verfügung.

Walter de Gruyter \& Co $\cdot$ Berlin 30 


\section{Ausgaben Deutscher Literatur des XV. bis XVIII. Jahrhunderts}

unter Mitwirkung von Käthe KaHLENBERG

herausgegeben von HANS-GERT ROLOFF

\section{Sebastian Brant \\ Tugent Spyl}

Nach der Ausgabe des Magister JohanN Winckel von Straßburg (1554)

herausgegeben von HANs-GeRT RoLoff (Berlin)

Oktav. IV, 165 Seiten. Mit 1 Bildnis. 1968. Ganzleinen DM 36,(Reihe Drama I)

\section{Das Künzelsauer Fronleichnamspiel}

herausgegeben von Peter K. Liebenow (Berlin)

Groß-Oktav. Mit 7 Kunstdrucktafeln. VI, 296 Seiten. 1969.

Ganzleinen DM 86,-

(Reihe Drama II)

Johannes Kerckmeister

Codrus

Ein neulateinisches Drama aus dem Jahre 1485 herausgegeben von Lothar MUNDT

Oktav. IV, 185 Seiten. Mit 2 Faksimiletafeln. 1969.

Ganzleinen DM 32,-

(Reihe Drama III)

Walter de Gruyter \& Co $\cdot$ Berlin 30 


\section{Ausgaben Deutscher Literatur des XV. bis XVIII. Jahrhunderts}

unter Mitwirkung von KÄTHE KaHLENBERG herausgegeben von Hans-GeRt RoLofF

\section{In Vorbereitung:}

Johannes Reuchlin (1455-1522), Werke. Etwa 10 Bände JohanN Beer (1655-1700), Sämtliche Werke Christian Weise (1642-1708), Sämtliche Werke Johann Geiler von KaIsersberg (1445-1510), Werke

Der Patriot (1724-1726). 3 Bände Philipp von Zesen (1619-1689), Sämtliche Werke Pamphilus Gengenbach (gest. 1524), Werke Wolfhart Spangenberg (etwa 1570-1636), Werke Teufelsbücher des 16. Jahrhunderts (in Auswahl) Johannes Agricola (etwa 1494-1566), Sprichwörter

\section{Reibe Drama}

Johannes Agricola (etwa 1494-1566)

Tragedia Johannis Huss (1537) und

Johann Vogelsang (d. i. Cochlaeus), Ein heimlich Gespräch von der Tragedia Johannis Hussen (1538)

Johannes Chryseus, Hofteufel (1545)

Gabriel Rollenhagen (1538-etwa 1622), Amantes amentes. Das ist Ein sehr Anmutiges Spiel von der blinden Liebe (1609)

Schauspiele der Wanderbühne 
